Journal of Behavior Therapy

PERGAMON

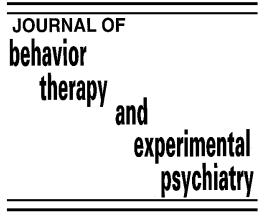

www.elsevier.com/locate/jbtep

\title{
A reattributional training program as a therapeutic strategy for fear of flying
}

\author{
Juan I. Capafóns*, Carmen D. Sosa, Conrado M. Viña \\ Department of Personality, Assessment and Psychological Treatments, Campus de Guajara, \\ University of La Laguna, Tenerife 38205, Spain
}

\begin{abstract}
In this study the results for the validation of a reattributional training program applied to the fear of flying are presented. The program is made up of $13( \pm 1)$ sessions and consists of three phases: Information; reattributional training; and the elaboration and application of the treatment designed by the patient with the help of the therapist. The program was applied to 24 patients while 24 other patients made up the waiting control group. The therapeutic success was evaluated by means of self-report scales, and by recording psychophysiological variables in a situation in which subjects viewed a video tape of a flight. Significant differences were obtained from the ANOVAs between experimental and control groups in all of the self-reported variables $(p<0.001)$ and in some of the psychophysiological variables $(p<0.05)$. The results support the effectiveness of the program. (C) 2000 Elsevier Science Ltd. All rights reserved.
\end{abstract}

Keywords: Reattributional training; Fear of flying; Flying phobia; Specific phobia; Cognitive therapy

\section{Introduction}

An examination of the existing bibliography reveals a relative scarcity of techniques or programs specifically designed for the resolution of fear of flying. Moreover, the few studies which do refer to this disorder often lack a correct multi-system assessment (cognitive, psychophysiological and motor) which would allow an adequate

* Corresponding author. Tel.: + 34-9-22-317477; fax: + 34-9-22-317461.

E-mail address: jcapafon@ull.es (J. I. Capafóns) 
evaluation of the applied treatment. Fear of flying, despite being a disorder whose incidence has increased considerably over recent decades, has raised little interest in the scientific community (Agras, Sylvester \& Oliveau, 1969; Arnarson, Tomasdottir \& Porsteinsson, 1992; Cummings, 1989; Deran \& Whitaker, 1980; Ekeberg, Seeberg \& Ellertsen, 1988,1989; Girodo \& Roehl, 1978; Nordlund, 1983; Sosa, Bastarrica, Herrero, Viña \& Capafóns, 1993).

Most of the authors agree in pointing out that the prevalence of this phenomenon is high (Between 45 and 50\% of the population suffers anything from a slight discomfort or apprehension to a very intense fear) and about $10 \%$ of the population suffers from such a high degree of fear or anxiety that it leads them to avoid this means of transport. We find ourselves then, faced with quite a common disorder that surprisingly has not received any special attention in the field of psychological treatment. Nevertheless, as Capafóns (1995) asserts, the phenomenon of fear of flying shows a complex framework of peculiarities and differential issues. Despite this being a specific phobia, we are also faced with a complex psychopathological phenomenon which needs an equally complex explanation.

The study presented here was subsidised by the Autonomous Government of the Canaries. It is part of a wider research project which deals with the subject of the fear of flying under three broad headings, the first of which refers to the preparation of valid and reliable instruments for the analysis of this problem (Capafóns, Sosa, Herrero \& Viña, 1997b; Sosa, Capafóns, Viña \& Herrero, 1995). The second refers to the study of this fear at a psychopathological level (Sosa et al., 1993) and finally, the third broad heading deals with different experimental intervention strategies aimed at eradicating this disorder (Capafóns, Sosa \& Avero, 1997a; Viña, 1996).

The need to generate different therapeutic modes for a single problem works on the evidence that people suffering from the same kind of psychological disorder, react in a very different way when the same psychological technique is applied to them (Capafóns, 1991,1995).

Taking the above as a starting point, the aim of the present study is the analysis of the therapeutic effectiveness of just one of the intervention programs which forms part of the above-mentioned research project, namely "Reattributional training".

Research on the attribution theories (Brehm, 1976; Davison \& Valins, 1969; De Vega, 1984; Forsterling, 1986; Heider, 1944,1958; Jones \& Nisbett, 1972; Kelley, 1967,1972; Langer, 1975; Nisbett \& Schachter, 1966; Schachter, 1964; Weary, Stanley $\&$ Harvey, 1989) has produced interesting results which have not however always generated concrete techniques which could be applied to the intervention of fears or phobias.

In the present study various interesting concepts from this theoretical field have been assembled, adding other contributions from self-management theories (Kanfer \& Gaelick, 1986) as well as from self-efficacy theory (Bandura, 1977) in order to work out a standardized intervention program which consists of $13( \pm 1)$ sessions, grouped in three differentiated phases: informative phase, attributional phase and solution application phase, which will be explained later. 


\section{Method}

\subsection{Sample}

Of the 96 subjects who comprised the sample group of this study, 48 (those with strong fear of flying) were recruited by means of an advertising campaign organized by this research team through the press, radio and TV. In the campaign, information was given concerning a free intervention program aimed at eliminating the fear of flying by plane. These 48 subjects had an intense fear while the other 48 subjects were included in the Non-fear group as they represented people who did not experience any feeling of anxiety about flying at all. Several requirements were taken into account when selecting the subjects with fear of flying, one of the most important of which being that the patients themselves were seeking treatment. To a certain extent, this guaranteed a clinically relevant sample group.

Moreover, all the participants in the fear group, assessed by means of the IDG-FV interview (Sosa et al., 1993), fulfilled the necessary criteria for the diagnosis of [300.29] Specific phobia, Situational type (airplanes), according to the Diagnostic and Statistical Manual of Mental Disorders (APA, 1994; 4th Ed.). Also borne in mind was a criterion resulting from this clinical interview (IDG-FV), by means of which five different levels of fear of flying were established: No fear; Moderately low fear; Moderately high fear; High fear and Very high fear.

Only subjects belonging to the groups of Moderately high fear, High fear, and Very high fear were included in this study as fear of flying sample. The members of the Non-fear group were all classified into the No fear level.

In order to include fear of flying subjects in the study, the fact that they had never undergone psychological or psychiatric treatment for this disorder and that they were not taking any medication that could distort either the assessment or treatment processes were also points taken into consideration. Four subjects were rejected for the research due to these considerations, although they did receive treatment.

Broadly speaking, the sample group in this study came mostly from the Canary Autonomous Community.

As a result of the application of the selection criteria, the sample group was comprised of 48 subjects with strong fear of flying, of whom $34(70.83 \%)$ were female and $14(29.17 \%)$ were male. The age of these subjects ranged from 17 to $59 \mathrm{yr}$ $($ mean $=33.5$; sd $=9.07)$.

From the 48 subjects belonging to the Non-fear group, $30(62.50 \%)$ were female and $18(37.50 \%)$ were male. The age of these subjects ranged from 18 to $60 \mathrm{yr}$ (mean $=32.3$; sd $=9.9$ ).

The sample group that suffered from fear of flying was divided into two groups: waiting control group and experimental group.

Table 1 shows the distribution of the variables gender, age and occupation of these groups.

The ratio men/women in the sample (fear of flying) group was 2.43 females to one male. This corresponds with prevalence studies which show a greater number of females with this disorder. Furthermore, both groups showed an identical distribution 
Table 1

Distribution of the three groups according to gender, age and occupation

\begin{tabular}{|c|c|c|c|c|c|c|}
\hline & \multicolumn{2}{|c|}{ Control G. } & \multicolumn{2}{|c|}{ Experim. G. } & \multicolumn{2}{|c|}{ Non-fear G. } \\
\hline & $N$ & $\%$ & $N$ & $\%$ & $N$ & $\%$ \\
\hline \multicolumn{7}{|l|}{ Gender } \\
\hline Males & 7 & 29.2 & 7 & 29.2 & 18 & 37.5 \\
\hline Females & 17 & 70.8 & 17 & 70.8 & 30 & 62.5 \\
\hline Total & 24 & 100.0 & 24 & 100.0 & 48 & 100.0 \\
\hline \multicolumn{7}{|l|}{ Age } \\
\hline$\leq 30$ aged & 10 & 41.7 & 8 & 33.3 & 21 & 43.8 \\
\hline $31-40$ aged & 11 & 45.8 & 9 & 37.5 & 17 & 35.4 \\
\hline$>40$ aged & 3 & 12.5 & 7 & 29.2 & 10 & 20.8 \\
\hline Total & 24 & 100.0 & 24 & 100.0 & 48 & 100.0 \\
\hline \multicolumn{7}{|l|}{ Occupation } \\
\hline Housewives, unemployed or retired pers & 3 & 12.5 & 4 & 16.7 & 6 & 12.5 \\
\hline Skilled workers & 3 & 12.5 & 3 & 12.5 & 6 & 12.5 \\
\hline Technicians & 5 & 20.8 & 5 & 20.8 & 9 & 18.8 \\
\hline Prof. with university qualification & 8 & 33.3 & 8 & 33.3 & 12 & 25.0 \\
\hline Students & 5 & 20.8 & 4 & 16.7 & 15 & 31.3 \\
\hline Total & 24 & 100.0 & 24 & 100.0 & 48 & 100.0 \\
\hline
\end{tabular}

in this variable. A large part of both groups ranged in age from 31 to $40 \mathrm{yr}$. Finally, with respect to the occupation variable, a broad selection of subjects from all types of occupational levels was present for both males and females. Accordingly both groups were essentially equivalent regarding the distribution of this variable.

Generally speaking, in both fear groups (waiting control group and experimental group) the similarities prevail over the differences. Chi-square analyses were carried out on three groups (experimental, control and non-fear group) for each of the demographic variables and no significant differences were found (Gender: Value: 0.75; D.F.: 2; Sign: 0.69. Age: Value: 2.49; D.F.: 4; Sign: 0.65. Occupation: Value: 2.44; D.F.: 8; Sign: 0.96).

Consequently, it may be concluded that any differences found when analysing both fear group scores would hardly be due to the influence of these socio-demographic variables.

\subsection{Instruments}

Six different instruments have been used in this study:

The assessment of heart rate and muscle tension was accomplished by two devices: Le 135 Cardioback and Le 136 Mioback from Letica Scientific Instruments. The data were monitored and recorded by an Epson XT mod. J-2 computer. The recording speed was approximately 1 sample/s. 
The third instrument used for assessment was a video tape of a flight. In a previous study (Capafóns et al., 1997b) the video tape has shown a difference between subjects with and without flying phobia with an acceptable level of reliability. Furthermore, this instrument was able to detect changes produced by psychological treatment in phobic patients, taking into account psychophysiological and self-report information.

The fourth instrument was the FFS (Fear of flying scale), used by Haug, Brenne, Johnsen, Berntzen, Gotestam \& Hugdahl (1987) in their works.

This scale has been factorized and psychometrically validated for Spanish speaking subjects by Sosa et al. (1995) and has shown adequate levels of reliability and validity. This scale assesses the different degrees of anxiety a person feels when faced with different situations associated with an actual flight.

The fifth instrument was the Gursky and Reiss's ESFF (Expectative scale for fear of flying; version of 1987), factorized and psychometrically validated for Spanish speaking subjects by Sosa et al. (1995). It also demonstrated high levels of reliability and validity. This questionnaire assesses two sources of fear: (1) the thoughts a person may have during a plane journey, relating to potential external harm (danger expectancies); and (2) the physiological events usually caused by anxiety that may occur during the flight (anxiety expectancies).

Further information about psychometric qualities and correlation on these scales can be found in Sosa et al. (1995).

The sixth instrument was a clinical interview (the IDG-FV) designed specifically by Capafóns (1991) for this research project. It consists of two parts: The first supplies general information such as labor information, personal relations, problems during childhood, and medical problems. The second part specifically relates to the fear of flying from its etiology to its symptomatology.

\subsection{Dependent variables}

The following measures were taken in the different assessment phases of pre/posttreatment and follow-up:

(A) The three scales of the FSS:

(1) Fear without self-involvement. This scale contains four elements relating to planes which do not directly involve the subject in the flight (e.g. looking at a flying airplane).

(2) Fear before the flight. This comprises eight situations prior to the flight itself in which the subject is involved (e.g. travelling to the airport - you are going to travel by plane).

(3) Fear during the flight. This contains nine elements relating to situations that occur between the moment of acceleration at take-off and the moment of landing (e.g. the airplane moves because of clouds or wind).

(B) Both scales of the ESFF:

(1) Danger expectancies scale. This is a composite of nine elements that contains perturbing thoughts (e.g. a wing might fall off). 
(2) Anxiety expectancies scale. This consists of 10 elements relating to disagreeable psychophysiological manifestations (e.g. your heart might pound or beat rapidly)

(C) Average psychophysiological indices of heart rate and muscle tension obtained during the video viewing, from 10 relevant and representative situations prior to taking the flight (packing suitcases; taxi to the airport; seeing the sign "Airport" from the motorway; arriving at the airport; seeing the sign "Departures"; checking-in; hearing the boarding call; standing up to board; seeing the plane and getting on to the plane) and averages of another 10 representative situations involving the flight itself in both variables (interior of the plane (I); looking out of the window; taxiing; accelerating on the runway; taking-off; interior of the plane (II); seeing clouds; seeing mountains; the approach and the landing).

The results obtained from each of these situations were divided according to the baseline which took place some minutes before each subject commenced viewing. During this time no feared stimulus was revealed. This was done to check whether during the video viewing the scores of the subjects increased or decreased with respect to their baseline and to diminish as far as possible any inter-subject variation in these variables. A score higher than one in any of the moments analysed would mean that this physiological variable had increased with respect to the baseline score (higher heart rate or greater muscular tension). A score lower than one would mean that this physiological variable had decreased.

\subsection{Intervention program}

This program, is applied to the patients individually in three differentiated phases. The first is the informative phase of two sessions each of which lasts approximately $45 \mathrm{~min}$. First, the therapist attempts to increase the patient's positive expectations about the therapy and about his or her self-efficacy. This is done by emphasizing that although fear of flying is a serious problem, the results of the patient's assessment have indicated that he/she will be able to deal with this successfully. Then the therapist, using examples from everyday life, explains the scientific concepts of "fear" and "phobia", and their differences. He also explains the learning and cognitive processes which cause and maintain them (classical conditioning, operant conditioning, observational learning and cognitive distortions). The aim is to enable the patient to have correct information on which to base the causal attribution of his/her problem. This is done because according to some authors (Lewis, 1972; Nisbett \& Ross, 1980; De Vega, 1984) having precise information about the processes of a phenomenon often leads one to make correct attributions about its causes and maintaining factors.

The second phase (attributional phase) consists of three sessions which are much more interactive than in the first phase. In these sessions the patient, with the therapist's help, carries out two basic tasks:

(a) Produce a functional scheme explaining what the factors are which cause and maintain his/her fear of flying. Brainstorming is used to achieve this aim, first in the fictitious case of a person with flying phobia and then in the case of the patient's own 
fear (the patient is instructed to take into account the objective information of the first phase).

(b) Produce an efficient intervention design aimed at eliminating his/her own fear of flying. Here again, brainstorming is used to generate solutions. Then when selecting these, the information about causal processes studied in the first phase and the causes and specific factors of the patient's fear are taken into account. In the process of selecting solutions, setting up intermediate goals, final goals and means of achieving these, the therapist advises and guides the patient without eclipsing his or her central role. The therapist's role in this phase is to encourage and reinforce the sense of self-importance of the patient in the therapeutic process. The patient must feel that he/she has been the one who has discovered the causes of and the solutions for his/her problem.

The third phase consists of approximately eight sessions in which the patient puts the procedures agreed on in the second phase into practice. The task of the therapist here is above all that of supervising and helping the patient with any possible problems which occur during this phase. The therapist has to reorient the patient if the latter departs from the initial design or, if this design does not prove to be minimally effective, suggest that a search be made for the causes of the failure and for pertinent solutions. The therapist also has to motivate and reinforce the gradual achievement of partial aims. He also has to emphasize that the achievements obtained are due to the patient's own efforts and that the changes observed in the fear of flying have taken place within the patient. Thus helping him/her to progressively take on the role of a person without fear of flying.

The intention of the program is to enable the patient to become an expert on his/her own fear. This allows the patient to feel responsible for and committed to the therapeutic process, having controlled his/her own treatment.

\subsection{Design of the study and procedure}

In this study an experimental design with repeated measures has been used with the fear of flying sample. All of the subjects were individually assessed under similar conditions by members of the research team. Subjects with fear were matched (as far as possible) according to demographic variables (Gender, Age and Occupation) and to fear variables (which will be commented on later), and then randomly assigned to one of either group. These groups were then randomly named waiting control group and experimental group. Both study groups (experimental and control) were assessed before and after the treatment (experimental group) or before and after the waiting period (control group).

Once the treatment/waiting period was finalized, the physiological measures were taken in the video exposure. Then all of the subjects were invited to go on a short inter-island flight of approximately half an hour (they had also been invited prior to the first stage of assessment but all of them refused to fly). After this flight, - seven days after the end of the treatment -, all the subjects were assessed through questionnaires (FFS and ESFF), and the clinical interview (IDG-FV). It should be mentioned that those subjects who experienced least improvement with the treatment, 
as well as the subjects in the control group declined the invitation to fly. Subjects from the experimental group who did not show any appreciable improvement $(N=3)$ and those who showed some improvement according to the instruments but still suffered some degree of significant anxiety $(N=4)$, were placed to another therapeutic program. Also, a further check-up of the "positive reacting group" (those subjects belonging to the experimental group that agreed to take the flight and that experienced some significant improvement measured through the dependent variables. $N=17$ ) was made after six months during which time these patients had made at least four flights.

\section{Data analysis}

In order to analyse the differences between both fear groups (control group and experimental group) before and after the treatment or waiting period, an analysis was made of each of the dependent variables, that is a $2 \times 2$ mixed analysis of variance (ANOVA) with a two-level (treatment/control) independent variable "inter" called "group" and also with another two-level (before/after) independent variable "intra" called "moment".

At the same time, in order to see how the positive reacting group progressed, a $3 \times 1$ ANOVA with a three-level (pre-treatment/post-treatment/follow-up) independent factor "intra" for each of the dependent variables was carried out.

Multivariate analyses were carried out to determine the variables contributing most to differentiating the two groups (control-experimental) and which subjects were classified in one or the other. Specifically, discriminant analyses were used.

Likewise, a discriminant analysis was used in order to assess to what extent both groups differed in post-treatment from the non-fear group. The two groups together with the above-mentioned non-fear group were specifically analysed with respect to which subject was allocated to which group. The variables included in this discriminant analysis were the most representative of the whole set, selected by the analysis of the correlations resulting from the validation studies of the subjective scales of fear of flying (Sosa et al., 1995) as well as the video tape exposure variables (Capafóns et al., 1997b).

\section{Results}

Table 2 shows means and standard deviations obtained from both fear groups before and after treatment.

The $2 \times 2$ ANOVA statistical data is shown in Table 3 .

Regarding the self-report scales (see Table 3), the ANOVA results are highly significant from the point of view of interaction in all cases: Fear without selfinvolvement (FWS: F $1.46=19.41, p<0.001$ ). Fear before the flight (FBF: $\mathrm{F} 1.46=52.17, p<0.001$ ). Fear during the flight (FDF: F $1.46=74.81, p<0.001$ ). Danger expectancies scale (DES: F $1.46=18.38, p<0.001$ ). Anxiety expectancies scale (AES: F $1.46=48.00, p<0.001)$. 
Table 2

Means and standard deviations of dependent variables in control $(N=24)$ and experimental $(N=24)$ groups, in both stages of assessment

FWS FBF FDF DES AES HRB HRD MTB MTD

Control G.

Pre-treat.

FWS

$\begin{array}{lllrrrrrrrr}\text { Pre-treat. } & \text { X } & 2.25 & 24.38 & 26.17 & 10.75 & 26.29 & 1.01 & 1.02 & 1.29 & 1.33 \\ & \text { sd } & 1.54 & 5.73 & 5.62 & 4.47 & 4.97 & 0.06 & 0.06 & 0.42 & 0.48 \\ \text { Post-treat. } & \text { X } & 3.04 & 24.04 & 26.08 & 11.04 & 26.54 & 1.01 & 1.02 & 1.26 & 1.33 \\ & \text { sd } & 2.60 & 7.50 & 5.76 & 5.61 & 6.13 & 0.04 & 0.04 & 0.36 & 0.45\end{array}$

Experimental G.

\begin{tabular}{lllrrrrrrrr} 
Pre-treat. & $\mathrm{X}$ & 2.92 & 25.71 & 26.50 & 12.17 & 27.92 & 1.02 & 1.03 & 1.22 & 1.32 \\
& $\mathrm{sd}$ & 2.73 & 5.64 & 5.61 & 6.76 & 6.40 & 0.06 & 0.06 & 0.28 & 0.51 \\
Post-treat. & $\mathrm{X}$ & 0.71 & 10.88 & 11.00 & 5.96 & 15.67 & 0.99 & 0.99 & 1.02 & 1.09 \\
& $\mathrm{sd}$ & 1.43 & 6.38 & 6.57 & 5.7 & 8.67 & 0.03 & 0.02 & 0.27 & 0.38 \\
\hline
\end{tabular}

Table 3

Anovas' F scores (both groups before and after treatment/waiting period)

\begin{tabular}{lcccccccll}
\hline & FWS & FBF & FDF & DES & AES & HRB & HRD & MTB & MTD \\
\hline Group $\times$ moment & 19.41 & 52.17 & 74.81 & 18.38 & 48.00 & 0.80 & 3.58 & 3.57 & 4.00 \\
$\quad$ interaction & $* * *$ & $* * *$ & $* * *$ & $* * *$ & $* * *$ & n.s. & n.s. & n.s. & n.s. \\
Group main effect & 2.55 & 14.84 & 25.77 & 1.56 & 7.37 & 0.07 & 0.28 & 3.07 & 1.06 \\
& n.s. & $* * *$ & $* * *$ & n.s. & $* *$ & n.s. & n.s. & n.s. & n.s. \\
Moment main effect & 4.33 & 57.08 & 76.43 & 15.23 & 44.23 & 2.98 & 3.81 & 6.33 & 3.96 \\
& $*$ & $* * *$ & $* * *$ & $* * *$ & $* * *$ & n.s. & n.s. & $*$ & n.s. \\
& & & & & & & & & \\
Simple effects & & & & & & & & & \\
Control group $\times$ moment & 2.70 & 0.06 & 0.00 & 0.07 & 0.04 & 0.35 & 0.00 & 0.20 & 0.00 \\
& n.s. & n.s. & n.s. & n.s. & n.s. & n.s. & n.s. & n.s. & n.s. \\
Experimental group & 21.04 & 109.2 & 151.2 & 33.53 & 92.19 & 3.36 & 7.23 & 9.70 & 8.77 \\
$\quad \times$ moment & $* * *$ & $* * *$ & $* * *$ & $* * *$ & $* * *$ & n.s. & $* *$ & $* *$ & $* *$ \\
Group $\times$ pre-test & 1.08 & 0.66 & 0.04 & 0.73 & 0.96 & 0.13 & 0.46 & 0.41 & 0.01 \\
& n.s. & n.s. & n.s. & n.s. & n.s. & n.s. & n.s. & n.s. & n.s. \\
Group $\times$ post-test & 14.88 & 42.92 & 71.52 & 9.52 & 25.19 & 1.18 & 5.15 & 6.69 & 3.89 \\
& $* * *$ & $* * *$ & $* * *$ & $* *$ & $* * *$ & n.s. & $*$ & $*$ & n.s. \\
\hline
\end{tabular}

An analysis by cells revealed no significant differences in these variables between the two groups (group $\times$ pre-test) in the first stage of assessment. The control group did not experience any significant changes after the waiting period (control group $\times$ moment). However, the experimental group did experience a highly significant decrease in all of these variables in the second stage of assessment (after treatment). See experimental group $\times$ moment. 
The progress in the experimental group, is confirmed by significant differences found in the second stage of assessment between both groups (group $\times$ post-test).

With regard to the psychophysiological records from the video exposure, no significant interaction effects were obtained. One significant main effect, the "moment" factor in the variable "muscle tension" before the flight (MTB: F $1.46=6.33, p<0.05$ ), was found. Nevertheless, analysis by cells reveals (1) an absence of differences between both groups in the pre-test; (2) no differences in the control group after the waiting period; and (3) significant differences in three of the four variables in the experimental group after treatment: Heart rate during the flight (HRD: F $1.46=7.23, p<0.01$ ). Muscle tension before the flight (MTB: F $1.46=9.70$, $p<0.01$ ). Muscle tension during the flight (MTD: F $1.46=8.77, p<0.01$ ).

At the same time, significant differences in two variables between both groups in the post-test were observed: Heart rate during the flight (HRD: F $1.46=5.15, p<0.05$ ). Muscle tension before the flight (MTB: F $1.46=6.69, p<0.05$ ).

The discriminant analysis carried out between both groups before the treatment/ waiting period, showed that the discriminant function was not able to differentiate accurately between both groups in the first stage of assessment. The function did not reveal any significant changes in Rao's V; the canonical correlation was low (0.24); Wilk's lambda value was very high (0.94) and the percentage of cases correctly classified was $56.3 \%$. However, in the second stage of assessment the discriminant function did prove to be effective in separating both groups - showing thus, a statistically significant function $(p<0.001)$; significant changes in Rao's $\mathrm{V}(p<0.001$; $p<0.05$ ); high canonical correlation (0.78) and $89.6 \%$ of cases correctly classified.

The results of the discriminant analysis between the fear of flying groups (Control and Experimental) and the non-fear group, reflected to what extent fear groups in the second stage of assessment differ from an extreme non-fear group.

This time the function obtained was statistically significant $(p<0.001)$; the variables included brought about significant changes in Rao's $\mathrm{V}(p<0.001 ; p<0.05)$; the canonical correlation was high (0.75) and the centroids showed an acceptable degree of detachment $(1.09 ;-1.12)$.

With regard to the percentage of correctly classified cases, it can be said that the function classified all the subjects $(100 \%)$ that belonged to the non-fear group correctly. However, the same did not occur with the fear groups (control and experimental) since $70.2 \%$ of the subjects were allocated to the fear groups and $29.8 \%$ to the non-fear group.

When a more detailed analysis was carried out to decide which particular subjects were to be classified in each group, all the subjects belonging to the control group were to be found correctly classified in the fear groups. Moreover, three subjects belonging to the experimental group and who had already been catalogued as therapeutic failures were also allocated to these groups according to the discriminant function.

Lastly and most interestingly, 14 subjects belonging to the fear groups and allocated, according to the function, to the non-fear group all belonged to the experimental group. According to the discriminant function, then, out of 24 subjects with strong fear of flying, 14 showed no fear of flying after having undergone the treatment. 
Moreover, the evolution of both groups in the five levels of fear of flying (IDG-FV criteria) was quite different. While in the control group at the second stage of assessment 23 subjects remained in the categories of very high fear and high fear, in the experimental group only three subjects remained in these categories. In the control group at the second stage of assessment there were no subjects in the categories of moderately low fear or no fear. Contrastingly, in the experimental group at the second stage of assessment, 17 subjects were located in these categories.

The results obtained by comparing the three stages of assessment (pre-treatment/post-treatment/follow-up) in the positive reacting group $(N=17)$ are presented in Table 4. This table shows the means of the dependent variables in the three "measurement" moments. The ANOVA results can be seen in Table 5.

These results confirm that the positive effects obtained through the intervention program in the positive reacting group have been maintained after six months.

Not only the main effect "moment", but also the comparisons between pre/posttreatment, post-treatment/follow-up and pre-treatment/follow-up help to confirm the long-term maintenance of therapeutic gains (positive progress as well as the sustained improvement of this group).

Table 4

Means and standard deviations of dependent variables at the three stages of assessment, in the positive reacting group $(N=17)$

\begin{tabular}{lllrrrrrrrr}
\hline & & FWS & FBF & FDF & DES & AES & HRB & HRD & MTB & MTD \\
\hline Pre-treat. & X & 2.29 & 24.88 & 26.24 & 11.00 & 26.71 & 1.03 & 1.03 & 1.23 & 1.39 \\
& sd & 2.42 & 5.79 & 5.59 & 6.10 & 5.97 & 0.06 & 0.07 & 0.33 & 0.60 \\
Post-treat. & X & 0.18 & 8.00 & 8.06 & 3.94 & 11.53 & 0.99 & 0.99 & 1.04 & 1.14 \\
& sd & 0.53 & 2.69 & 3.67 & 3.27 & 5.21 & 0.02 & 0.02 & 0.31 & 0.44 \\
Follow-up & X & 0.06 & 8.94 & 9.29 & 4.35 & 11.94 & 1.00 & 0.99 & 1.01 & 1.02 \\
& sd & 0.24 & 2.51 & 2.95 & 2.45 & 4.52 & 0.02 & 0.02 & 0.09 & 0.10 \\
\hline
\end{tabular}

Table 5

Anovas' $\mathrm{F}$ scores of the positive reacting group at the three stages of assessment: pre-treatment/posttreatment/follow-up $(N=17)$

\begin{tabular}{llllllllll}
\hline & FWS & FBF & FDF & DES & AES & HRB & HRD & MTB & MTD \\
\hline Moment main effect & 12.62 & 100.1 & 117.7 & 20.32 & 155.7 & 5.31 & 5.99 & 6.95 & 5.46 \\
& $* * *$ & $* * *$ & $* * *$ & $* * *$ & $* * *$ & $*$ & $* *$ & $* *$ & $* *$ \\
First vs. & 12.23 & 105.7 & 121.7 & 22.18 & 151.9 & 5.97 & 6.79 & 26.59 & 8.51 \\
second a.s. & $* *$ & $* * *$ & $* * *$ & $* * *$ & $* * *$ & $*$ & $*$ & $* * *$ & $*$ \\
Second vs. & 0.65 & 8.33 & 14.28 & 1.44 & 1.05 & 0.00 & 0.07 & 0.11 & 1.22 \\
third a.s. & n.s. & $*$ & $* *$ & n.s. & n.s. & n.s. & n.s. & n.s. & n.s. \\
First vs. & 13.72 & 98.05 & 117.8 & 19.45 & 181.3 & 5.92 & 6.14 & 8.46 & 6.63 \\
third a.s. & $* *$ & $* * *$ & $* * *$ & $* * *$ & $* * *$ & $*$ & $*$ & $*$ & $*$ \\
\hline
\end{tabular}




\section{General discussion}

Omitting the nonspecific treatment effects, the results obtained indicate that the intervention program tested in this study had beneficial effects on people suffering from fear of flying (specific phobia according to DSM-IV; APA, 1994). These effects are evident in the psychophysiological variables as assessed in the video of a flight and especially with respect to the self-report variables. In the latter, the differences found between the control and experimental groups are highly significant. The lesser degree of differences obtained in the psychophysiological variables may be due either to the measurement instruments used, since it was not an actual flight situation, or to the lesser effect of the intervention on this type of response. It may be that portable poligraphy in a real-life situation could bring to light more clarifying information.

The methodology used in this study allows us to assume on the one hand, that this therapeutic program produced a considerable degree of effectiveness. It may also be assumed that the improvement is due to the treatment and not to the mere lapse of time or to any fortuitous events that may have occurred during the period. At the same time, the six months follow-up analysis shows some consolidation of the positive results.

The program has shown substantial clinical validity. Regarding the degree of effectiveness at a multivariate level, the results are quite encouraging since a large percentage of the experimental group $(58.3 \%)$ has shown no fear of flying after having undergone the treatment. Indeed, subjects within this percentage were equivalent to the non-fear group in fear of flying according to the discriminant function. Moreover, only $12.5 \%$ of the subjects of the experimental group have been catalogued as therapeutic failures. (The rest of the subjects have obtained a certain degree of improvement.)

This type of study outlines the importance that the use of attribution might have in the field of fears and phobias. Initial therapeutic work with the patient in which the acquisition mechanisms of the fear are insisted on, may later strengthen the undoubted efficacy of behavioral techniques.

There is a need to pinpoint which variables can clearly predict which people are suitable for this kind of treatment. This problem is currently being investigated and some preliminary data have been obtained that indicate the possibility of prescribing this treatment to patients with specific characteristics (Capafóns, Sosa, Viña \& Avero, 1997c).

\section{References}

Agras, S., Sylvester, D., \& Oliveau, D. (1969). The epidemiology of common fears and phobias. Comprehensive Psychiatry, 10, 151-156.

American Psychiatric Association (1994). Diagnostic and statistical manual of mental disorders (4th ed.). Washington, DC: Author.

Arnarson, E. Ö., Tomasdottir, N. H., \& Porsteinsson, E. B. (1992). A cognitive-behavioural treatment of fear of flying; 16-30 months follow-up. Paper presented at the XXII Annual Congress of the European Association of Behaviour Therapy, Coimbra, Portugal. 
Bandura, A. (1977). Self-efficacy: toward a unifying theory of behavioral change. Psychological Review, 84, 191-215.

Brehm, S. S. (1976). The application of social psychology to clinical practise. Washington: Hemisphere.

Capafóns, J. I. (1991). Estudio psicopatológico y estrategias de intervención para la fobia a volar en transporte aéreo [Psychopathological study and intervention strategies for air travel phobia]. Partial report corresponding to the first year of investigation. Consejería de Educación, Cultura y Deportes del Gobierno Autónomo de Canarias. Mineo.

Capafóns, J. I. (1995). Fobia a viajar en transporte aéreo: estudio de los determinantes del éxito terapéutico [Air travel phobia: study of determinants of therapeutic success]. Final report corresponding to the third year of investigation. Consejería de Educación, Cultura y Deportes del Gobierno Autónomo de Canarias. Mineo.

Capafóns, J. I., Sosa, C. D., \& Avero, P. (1997a). La desensibilización sistemática en el tratamiento de la fobia a viajar en transporte aéreo [Systematic desensitization as a treatment for flying phobia]. Psicothema, 9(1), 17-25.

Capafóns, J. I., Sosa, C. D., Herrero, M., \& Viña, C. M. (1997b). The assessment of fear of flying: elaboration and validation of a video-tape as an analogous situation of a flight. European Journal of Psychological Assessment, 13, 118-130.

Capafóns, J. I., Sosa, C. D., Viña, C. M., \& Avero, P. (1997c). Fobia a viajar en avión: valoración y predicción de resultados de dos programas terapéuticos [Flying phobia: Evaluation and prediction of the outcomes from two therapeutical programs]. Ansiedad y Estrés, 3(2-3), 265-287.

Cummings, T. W. (1989). Flying Phobia. In C. Lindemann, Handbook of phobia therapy: rapid symptom relieve in anxiety disorders. Northvale, $\mathrm{NJ}$ : Erlbaum.

Davison, G. C., \& Valins, S. (1969). Maintenance of self-attributed and drug attributed behavior change. Journal of Personality and Social Psychology, 11, 25-33.

Deran, R., \& Whitaker, K. (1980). Fear of flying: impact on the U.S. air travel industry (\# BCS-00009$\mathrm{RO} / \mathrm{OM})$. Boeing Company Document.

De Vega, M. (1984). Introducción a la psicología cognitiva [Introduction to cognitive psychology]. Madrid: Alianza Editorial.

Ekeberg, O., Seeberg, I., \& Elertsen, B. B. (1988). The prevalence of flight anxiety in Norwegian airline passengers. Scandinavian Journal of Behaviour Therapy, 17, 213-222.

Ekeberg, O., Seeberg, I., \& Elertsen, B. B. (1989). The prevalence of flight anxiety in Norway. Nord Psykiatr Tidsskr, 43, 443-448.

Forsterling, F. (1986). Attributional conceptions in clinical psychology. American Psychologist, 41, $275-285$.

Girodo, M., \& Roehl, J. (1978). Cognitive preparation and coping self-talk: Anxienty management during the stress of flight. Journal of Consulting and Clinical Psychology, 46, 978-989.

Gursky, D. M., \& Reiss, S. (1987). Identifying danger and anxiety expectancies as components of common fears. Journal of Behaviour Therapy and Experimental Psychiatry, 18, 317-324.

Haug, T., Brenne, L., Johnsen, B. H., Berntzen, D., Gotestam, K. G., \& Hugdahl, K. (1987). A three-systems analysis of fear of flying: a comparison of a consonant vs. a non-consonant treatment method. Behaviour Research and Therapy, 25(3), 187-194.

Heider, F. (1944). Social perception and phenomenal causality. Psychological Review, 51, 358-374.

Heider, F. (1958). The psychology of interpersonal relations. New York: Wiley.

Jones, E. E., \& Nisbett, R. E. (1972). The actor and the observer: divergent perceptions of the causes of behavior. In E. E. Jones, D. E. Kanouse, H. H. Kelley, R. E. Nisbett, S. Valins, \& B. Weiner, Attribution: Perceiving the causes of behavior. Morristown, NJ: General Learning Press.

Kanfer, F. H., \& Gaelick, L. (1986). Self-Management methods. In F. H. Kanfer \& A. P. Goldstein, Helping people change: A textbook of methods (3rd ed., pp. 283-345). New York: Pergamon Press Inc.

Kelley, H. H. (1967). Attribution theory in social psychology. In D. Levine, Nebraska symposium on motivation. Lincoln: University of Nebraska Press.

Kelley, H. H. (1972). Causal schemata and the attribution process. Morristown, NJ: General Learning Press.

Langer, E. J. (1975). The illusion of control. Journal of Personality and Social Psychology, 32, 311-328.

Lewis, D. J. (1972). We, the navigators. Australian National University Press. 
Nisbett, R., \& Ross, L. (1980). Human inference. Strategies and shortcomings of social judgement. Englewood Cliffs, NJ: Prentice-Hall.

Nisbett, R. E., \& Schachter, S. (1966). Cognitive manipulation of pain. Journal of Experimental Social Psychology, 2, 257-276.

Nordlund, C. L. (1983). A questionnaire of Swedes' fear of flying. Scandinavian Journal of Behaviour Therapy, $12,150-168$.

Schachter, S. (1964). The interaction of cognitive and physiological determinants of emotional state. In L. Berkowitz, Advances in experimental social psychology. New York: Academic Press.

Sosa, C. D., Bastarrica, C., Herrero, M., Viña, C. M., \& Capafóns, J. I. (1993). Estudio descriptivo de la fobia a volar a través de la entrevista IDG-FV [Descriptive study of the flying phobia through the IDG-FV interview]. Paper presented at the XXIV Congreso Interamericano de Psicología, Santiago de Chile, Chile.

Sosa, C. D., Capafóns, J. I., Viña, C. M., \& Herrero, M. (1995). La evaluación del miedo a viajar en avión: Estudio psicométrico de dos instrumentos de tipo autoinforme [The assessment of fear of flying: Psychometric study of two self-report instruments]. Psicología Conductual, 3, 133-158.

Viña, C. M. (1996). Un programa basado en entrenamiento reatribucional como estrategia de intervención para la fobia a viajar en avión [A reatributional training based program as an intervention strategy for air travel phobia]. Unpublished doctoral thesis, Universidad de La Laguna, La Laguna, Santa Cruz de Tenerife, Spain.

Weary, G., Stanley, M. A., \& Harvey, J. H. (1989). Attribution. New York: Springer. 